\title{
GLOBALISASI PEMIKIRAN KEAGAMAAN MUHAMMADIYAH
}

\author{
Muhammad Abdul Halim Sani' ${ }^{1}$ Ilham ${ }^{2}$ \\ 1,Prodi Psikologi, Universitas Muhammadiyah Prof. DR HAMKA \\ 2Prodi PBI, Universitas Muhammadiyah Mataram, Indonesia \\ mabdulhalimsani@uhamka.ac.id11, ilhamsuri2015@gmail.com² $^{2}$
}

\section{INFO ARTIKEL}

\section{Riwayat Artikel:}

Diterima: 02 -03 -2021

Disetujui: 30 -04 -2021

\section{Kata Kunci:}

Globalisasi,

Internasinalisasi,

Pemikiran Keagamaan

Muhammadiyah.

\section{Key word}

Globalization,

Internalization,

Religious concept of

Muhammadiyah.

\begin{abstract}
ABSTRAK
Abstrak: Penelitian ini bertujuan untuk memahami globalisasi sebagai media pemikiran keagamaan Muhammadiyah dan untuk menggambarkan bentuk pemikiran keagamaan Muhammadiyah. Penelitian ini menggunakan metode deskriptif kualitatif dengan ubjek penelitian organisasi persyarikatan Muhammadiyah, menggunakan Intrumen dokumen dan wawancara. Metode analisis data menggunakan pengumpulan data, reduksi data, penyajian, dan penarikan kesimpulan. Berdasarkan hasil analisis data bahwa agama merupakan rahmat dan meliputi seluruh aspek kehidupan dan Globalisasi sebagai realitas sosial semakin berkembang pesat didukung dengan teknologi informasi khususnya internet sehingga batas Negara dan waktu terasa pudar. Masyarakat Indonesia sebagai penduduk muslim mayoritas memiliki peranan sosial yang dalam memberikan pandangan baru terhadap tatanan keislaman dunia. Hal ini dikarenakan keislaman Indonesia menarik yakni moderat, dan demokratis yang diwakili oleh ormas keagamaan Muhammadiyah dan NU. Artikel ini ingin mengkaji konsep internalisasi pemikiran keagamaan Muhammadiyah dengan bersinergi dengan globalisasi sebagai wakil ormas yang moderat, respon terhadap wajah islam dunia mainstream di Timur Tengah. dan peengenalaan keislaman kepada dunia
\end{abstract}

\section{A. LATAR BELAKANG}

Kata 'globalisasi' pada tahun 1990an menjadi kata yang istimewa dalam mendeskripsikan keadaan dunia yang mengalami perubahan yang mendasar dan signifikan. (Weiss, 2000) Diskursus globalisasi dikenal sebagai era globalisasi (the age of globalization). Kemunculan diskursus itu, dikarenakan dua hal yakni runtuhnya Uni Soviet dan perkembangan teknologi yakni teknologi informasi. Teknologi informasi ini, menjadikan dunia dapat diakses dalam waktu sekejap sehingga memudarnya batas ruang dan waktu. Globalisasi ditandai dengan perkembangan teknologi informasi berdampak pada persoalan-persoalan yang lain seperti: pendidikan, agama, sosial, politik, budaya, ilmu pengetahuan, teknologi. (Sujati, 2018, h.98)
Menurut para ilmuan banyak yang sepakat bahwa abad ke-16 di Eropa dianggap sebagai original source munculnya globalisasi. Perkembangan di Eropa saat itu telah membuat dunia semakin terhubung satu sama lain. Interaksi manusia dalam cakupan geografis semakin intens dalam wujud migrasi, dan aktivitas ekonomi dalam wujud perdagangan semakin meningkat dalam beberapa negara. Dalam perkembangan selanjutnya, pemahaman dan pemaknaan globalisasi semakin kompleks dari konteks sejarahnya tersebut. (Chaudhary 2005, h.139) Istilah globalisasi diperdebatatkan dengan mempertanyakan istilah itu muncul, serta konsekuensinya serta posisi politik dunia yang berbeda. Adapula yang berpendapat bahwa globalisasi merupakan mitos yang melanjutkan tren lama yang telah mapan, dan sisi 
lain kebijakan yang tidak real dan maju dalam perkembannya. (Giddens, 2019, h.32)

Sedangkan istilah yang lain, globalisasi dalam konsep sosiologi yang menggambarkan berbagai macam varian perubahan signifikan yang terjadi dalam kehidupan masyarakat dunia. Munculnya wacana globalisasi dapat ditelisik dari essai Immanuel Kant (1795) tentang kedamaian abadi (perpetual peace) melalui penciptaan satu sistem terintegrasi untuk seluruh bangsa di dunia. Pandangan tersebut bersumber pada pengalaman perang tak berkesudahan antarbangsa di Eropa selama rentang waktu 1618-1648 yang berakhir dengan penegasan teritorialisasi. Seruan akan adanya etika komunitas tunggal (single community ethic) menjadi acuan utama untuk menuju liberalisme kosmopolitan dunia. Kapitalisme mendorong globalisasi tidak lagi dimaknai sebagai interkonektivitas wilayah di dunia, namun sebagai arena aneksasi wilayah di dunia untuk mendapatkan sumber ekonomi. Maka dalam hal ini, globalisasi dipahami sebagai tahapan linearitas evolusi kapitalisme sejak abad 18 yang cakupannya meliputi kolonialisme, pembangunanisme, dan kini neoliberalisme. (Jati, 2013, h.243)

Globalisasi dalam ekonomi memiliki kesan negative perkembangan dari sifat dan ciri fenomena kapitalisme global yang menjadi teras dan tumpuan dimensi globalisasi berkenaan. Kapitalisme menekankan ide dan amalan perdagangan bebas, liberalisasi pasar tanpa adanya kewenangan dari Negara. (Bakar, 2018, h.15) Ditandani dengan going global MNC di Amarika Serikat saat dunia bisnis banyak menggunakan kata tersebut dalam perkembangannya. (Weis, 2012, h.3) Globalisasi sebagai kepanjangan kapitalisme memunculkan aktor-aktor baru menandakan sifatnya yang multisiplitas yang kini menjadi determinasi dalam interaksi di tataran global. Isu-isu yang ada kini mulai beragam dan menyentuh esensi dasar untuk dikelola secara bersama dalam naungan governance antar berbagai actor dalam pengeolahan Negara yang tidak dapat dihindarkan dari perusahan internasional. (Kusumawardhana, 2017, h.284)

Selain itu, proses globalisasi dalam persfektif kebudayaan sebagai praksis dan wacana, maka kebudayaan tampak sebuah proses, sosoknya bersifat sementara, cair, dan tanpa batas-batas yang jelas. (Alam, 1998, h.7) Kecairan globalisasi ditandani dengan dengan adanya interaksi dan integrasi, pada akhirnya memengaruhi perubahan dunia di segala bidang kehidupan. Perubahan dunia beserta paradigmanya sebagai dampak dari globalisasi menunjukan sebuah proses multidimensi yang menuju pada sebuah tatanan dunia tanpa batas pemisah antarnegara (borderless). Sistem sosial mengalami perubahan sosial budaya suatu masyarakat di sudut manapun termasuk juga bagi Indonesia sebagai komunitas masyarakat global. (Thahir, 2014, h.279)

Indonesia sebagai salah satu negara penganut muslim mayoritas, merapakan salah satu warga dunia yang memiliki sifat keislaman yang khas selaras dengan demokratisasi, Hak Asasi Manusia, modernisasi, dan pembangunan. Pelaksanaan keagamaan umat Islam yang di motori oleh NU dan Muhammadiyah bersifat moderat dan progresif. Melihat keislaman Indonesia dapat menjadi alternative keislaman yang berada di Timur tengah yang serat dengan konflik sectarian. Oleh karena itu, tulisan ini akan membahas globalisasi upaya peluang internalisasi pemikiran dan gerakan keislaman Indonesia khususnya Muhammadiyah.

\section{B. METODE PENELITIAN}

Penelitian ini bertujuan untuk memahami globalisasi sebagai media dalam menglobalkan pemikiran keagamaan Muhammadiyah. Oleh karena itu, pendekatan yang dilakukan dalam penelitian ini adalah pendekatan kualitatif. Sebagaimana, yang dinyatakan Locke, Spriduso dan Silverman (1987) dalam Cresswell (2013, h.155); penelitian kualitatif adalah untuk memahami situasi sosial, peristiwa, peran, kelompok, atau interaksi tertentu yang bersifat deskripsif atau naratif.

Selain itu, penelitian ini bertujuan untuk menggambarkan secara mendalam, berdasarkan dukungan fakta dan informasi yang ada mengenai bentuk pemikiran pendidikan pembebasan dari kedua tokoh tersebut. Maka berdasarkan tujuan dari penelitian ini, masuk dalam jenis penelitian deskriptif-kritis. Sebagaimana, yang diungkapkan Natzir, tujuan penelitian deskriptif adalah untuk mendeskripsikan, menguraikan, menggambarkan, atau melukiskan secara mendalam, sistematis, faktual dan akurat mengenai fakta-fakta, sifat-sifat serta hubungan antara fenomena yang diteliti (Natzir, 2018, h.63).

Pengumpulan data yang dilakukan dalam penelitian ini menggunakan Studi Kepustakaan/ Dokumentasi. Pustaka yang dikaji dalam penelitian ini bersifat primer dan skunder. Setelah data diperoleh kemudian dipetakan, diinterpretasi, dan melakukan analisis sehingga menjadi sebuah pemikiran yang sistematis tentang globalisasi memberikan peran dalam mengglobalkan pemikiran kegamaan Muhammadiyah, sebagaimana diungkapkan oleh Nasution analisis telah mulai sejak merumuskan dan menjelaskan masalah, 
sebelum terjun ke lapangan/melakukan studi pustaka dan berlangsung terus sampai penulisan hasil penelitian (Sugiyono, 2015, h. 245).

\section{HASIL DAN PEMBAHASAN}

\section{Pemikiran Keagamaan Muhammadiyah}

Indonesia dengan penduduk yang mayoritas beragama Islam, dengan jumlah terbanyak di dunia, telah menjadi tempat yang subur bagi berkembangnya pemikiran dan gerakan Islam. Banyak pemerhati keagamaan ingin mengikuti perkembangan pemikiran dan gerakan Islam yang berkembang di dalam negeri, namun seringkali terkendala oleh faktor bahasa. Muhammadiyah dengan usianya yang melampaui satu abad, dengan kekayaan amal usahanya, terutama di bidang pendidikan, sosial dan kesehatan yang berkontribusi signifikan bagi pembangunan bangsa Indonesia, sudah saatnya untuk melakukan internasionalisasi pemikiran dan gerakannya. (Santoso, 2016, h.31)

Muhammadiyah menafsirkan normativitas agama untuk dipakai sebagai dasar beragama dan sekaligus sebagai landasan bagi reformasi sosial. Keyakinan atau sistem kepercayaan akan teraktualisasikan secara eksternal kedataran realitas sosial dengan sistem pemikiran keagamaan. Oleh karena itu, melahirkan sikap sejuk dan toleran yang dimiliki oleh generasi awal Muhammadiyah. Pelaksanaan ajaran agamanya dalam bukan hanya dalam aspek ritual tetapi bersifat praksis sosial untuk memberdauayakan masyarakat. Ajaran tersebut menjadikan Islam sebagai rahmat dan meliputi segala aspek kehidupan. (Iyunk, 2020) Dalam kalam pendekatan digunakan, pembahasan tentang Tuhan (dalam pengertian klasik), dengan oreintasi pada sifat dan dzatNya, namun makna pendekatan mengacu pada fungsionalisasi nilai-nilai spiritualitas ke-Tuhan-an dalam aplikasi kehidupan konkret. (Santoso, 2016, h.31) Sebagaimana dalam karakteristik pemikiran Kiai Ahmad Dahlan terdeskripsikan dari cara pandangnya terhadap petama akal, kedua pemahaman keagamaan yang bersifat relatif, ketiga filsafat toleransi, keempat penafsiran agama yang tidak absolute, kelima iman, sholat, amal dan keenam tanggungjawab sosial. (Jainuri, 2019) Islam yang diamalkan oleh para tokoh awal muhammadiyah bercorak progresifberkemajuan merupakan kesatuan pengamalan dari Islam-Ihsan-Ilmu. Kegamaan yang tersebut berdiri dengan lima fondasi, pertama tauhid yang murni. Kedua, memahami al Qur'an dan as Sunnah secara mendalam. Ketiga, melembagakan amal sholih yang fungsional dan solutif. Keempat, orientasi kekinian dan masa depan. Kelima, toleran, moderat dan suka bekerjasama. (Mu'ti, 2019)
Pemikiran dan gerakan yang progresif dalam organisasi ditandani dengan cirinya sebagai berikut; Pertama, berfikir yang melampau zaman (futuristik, wal ashr), kedua tauhid yang murni (alladina amanu). Ketiga, pelembagaan ide kreatif menjadi amal sholeh sebagai wujud kerja dalam membangun peradaban (wa amilus sholihah). Keempat, berpijak pada al Qur'an dan as Sunnah dalam pengembangan ilmu pengetahuan dan teknologi sehingga terintegrasi (tawashabil haqq). Kelima, toleran, rendah hati, menebar cinta kasih sayang, perdamaian dan dapat bekerjasama (tawashabil shabr). (Baidhawy dan Khoirudin, 2017)

Pemikiran pendiri Muhammadiyah itu terlembagakan kedalam Majelis Tarjih Pimpinan Pusat Muhammadiyah. Majelis tarjih berfungsi penerjemahan al Qur'an dan as Sunnah sehingga menjadi pegangan bagi masyarakat. Berikut ini merupakan pokok-pokok Manhaj Tarjih. Secara garis besar dirumuskan beberapa prinsip, antara lain: (1) sumber dalam beristidlâl; (2) ketidak-terkaitan pada satu mazhab tertentu; (3) penggunaan akal dalam menyelesaikan masalah duniawi; (4) dan yang terpenting adalah terumuskannya metode-metode ijtihad, yaitu: ijtihad bayânî, qiyâsî, dan istishlâhî. Ijtihad bayânî dipakai dalam rangka mendapatkan hukum dari nash (teks) dengan menggunakan dasardasar tafsir. Ijtihad qiyâsî digunakan dalam rangka untuk menetapkan hukum yang belum ada dalam nash, dengan memperhatikan kesamaan 'illat-nya. Sementara ijtihad istishlâhî digunakan untuk menetapkan hukum yang sama sekali tidak diatur dalam nash. Selanjutnya dalam mengembangkan pemikiran islam perlu pengembangan pendekatan mahami al al Qur'an dan as Sunnah dalam menjadi pendekatan bayânî, burhânî, dan 'irfânî. Pendekatan bayânî merupakan pendekatan yang menempatkan nash sebagai sumber kebenaran dan sumber norma untuk bertindak, sementara akal hanya menempati kedudukan yang sekunder dan berfungsi menjelaskan dan menjustifikasi nash yang ada. (Djamil, 2015, h,83-106)

$$
\text { Pendekatan 'irfânî adalah pendekatan }
$$
pemahaman yang bertumpu pada instrumen pengalaman batin: dzauq, qalb, wijdân, bashîrah dan ilhâm. Pengetahuan yang diperoleh melalui pendekatan ini biasanya disebut pengetahuan dengan kehadiran (hudhûrî), suatu pengetahuan yang berupa inspirasi langsung yang dipancarkan Allah ke dalam hati orang yang jiwanya selalu bersih. Intuisi dapat menjadi sumber awal bagi pengetahuan, setidaknya menjadi sumber inspirasi pencarian hipotesis. Dalam pengamalan agama dan bersikap baik terhadap orang lain, hati nurani dan kalbu manusia dapat menjadi sumber bagi kedalaman penghayatan agama, kekayaan rohani dan kepekaan 
batin. Sedangkan bagi ijtihad hukum, intuisi dan kalbu manusia dapat menjadi sumber pencarian hipotesis hukum, juga pembuktian akhir terletak pada bukti-bukti bayânî dan burhânî. Ketiga pendekatan tersebut; bayânî, burhânî, dan 'irfânî, telah dijadikan pedoman bagi warga Muhammadiyah dalam berpikir, terutama dalam memahami dan menyelesaikan masalah-masalah muamalah. (Anwar, 2015, h.63-81)

Landasan epistemologi manhaj ijtihad Muhammadiyah adalah inti pengalaman agama dalam Islam sendiri tertuang dalam pandangan hidup Islami, yaitu tauhid. Secara metodologis, tauhid mengandung empat prinsip penting, di antaranya: (1) kesatuan kebenaran (wahdaniyyah alhaqîqah), (2) optimisme (at-tafâ'ul), (3) keragaman manifestasi (tanawwu'at-tajalliyât), dan (4) keterbukaan (al-infitâh), dan toleransi (at-tasâmuh). Kesatuan kebenaran, yang bersumber dari keyakinan tauhid bahwa Allah Maha Esa, berarti bahwa kebenaran dari berbagai sumber, baik dari wahyu Ilahi (al-bayân), dunia empiris (al-burhân), dan pengalaman batin manusia (al-'irfân), adalah satu dan tidak ada pertentangan diantaranya. (Keputusan Muktamar Muhammadiyah, 2000) Sistem ijtihad yang dilakukan oleh majelis Tarjih berimplikasi pada aksiologinya. Hal ini dikarenakan dalam aksiologi sebagai bekal awal, prinsip tujuantujuan syariah (maqâshid al-syarî́ah) dan prinsip maslahah untuk kemanusiaan dan alam dalam rangka beribah kepada Allah.

\section{Mengglobalkan Muhammadiyah}

Menurut pandangan Mariam Ait Ahmad, peneliti, penulis dan pemikir dari Maroko, dosen Universitas Ibn Tufayil, Rabat, Marokko menyatakan bahwa ingin sekali memahami dengan baik buah pikiran Muslim Indonesia yang unik, moderat dan progresif. Ia menjadi ketua persahabatan IndonesiaMaroko di Rabat. Ia mengagumi buah pikiran Muslim Indonesia, tetapi dari sumber tangan kedua (secondary resources). Indonesia sebagai negara mayoritas Muslim di dunia, yang menjalankan sistem demokrasi dalam negara-bangsa, bagaimana peran organisasi Muslim terbesar sebelum era kemerdekaan sampai sekarang, seperti Muhammadiyah (1912) dan Nahdlatul 'Ulama (1926), dalam merawat sistem negara-bangsa, hampir tidak bisa dikenali dengan baik karena langkanya buku atau literatur tentang pemikiran Islam Indonesia yang tertulis dalam bahasa Arab. Belum lagi yang terkait dengan hubungan agama (Islam) dengan budaya lokal yang sangat genuine, hubungan seni, budaya dan agama, sistem negara bangsa yang berbentuk kepulauan, munculnya neo- sufism (hubungan yang proporsional antara syariah/hukum dan tasawuf), living Qur'an dan living Sunnah dalam masyarakat Indonesia, perkembangan Dirasat Islamiyyah/Islamic Studies di perguruan tinggi agama di Tanah Air, hubungan antara agama dan negara (bukan teokrasi, bukan sekuler), sistem negara Pancasila, hubungan antara penganut agama-agama di Nusantara (Muslim 87 \%; Non-Muslim 13\%), civil society, peran wanita, peran umat Islam dalam program Keluarga Berencana, implementasi konstitusi dalam bernegara dan berbangsa. (Abdullah, 2016, h.4-5) Haedar
Nashir
mengatakan, gerakan go internasional itu pun telah dialakukan sejak dirintis oleh Ahmad Dahlan. Namun, saat itu masih sebatas relasi antara Islam di Indonesia dan Islam di Timur Tengah. Sejak awa tahun 2000-an, langkah itu pun dilanjutkan secara gradual atau bertahap. Sehingga, Muhammadiyah tak hanya bergerak dalam ranah domestik namun juga dalam ranah global yang lebih luas (Nashir, 2018. Muhammadiyah melakukan internasionalisasi pemikiran dan gerakan dikarena beberapa alasan. Pertama, karena tuntunan dan keniscayaan sejarah. Banyaknya permintaan dari berbagai institusi untuk Muhammadiyah berperan lebih besar. Permintaan tersebut diajukan berdasarkan pengalaman dan penilaian individu dan lembaga yang berinteraksi dan bekerjasama dengan Muhammadiyah (Mappanyompa, 2019).

Kedua, pembinaaan anggota Muhammadiyah di luar negeri sebagian juga karena permintaan Kedutaan Republik Indonesia di mancanegara. Ketiga, adanya peluang dan tantangan untuk memperkuat gerakan Muhammadiyah di dalam negeri dengan jaringan lembaga dan negara asing serta diaspora Muhammadiyah. Internasionalisasi dilaksanakan berbasis gerakan sosial, pendidikan, kebudayaan, dan kemanusiaan. (Mu'ti, 2018) Keempat, keberadaan PCIM yang kini telah ada di 32 negara di berbagai belahan benua yang ada di dunia. PCIM ini terdiri dari PCIM Kairo-Mesir, PCIM Republik Islam Iran, PCIM Khartoum - Sudan, PCIM Belanda, PCI Jerman, PCIM Inggris, PCIM Prancis, PCIM Amerika Serikat, PCIM Jepang, PCIM Turkey, PCIM Australia. Salah satu fungsi utama Pimbinan cabang istimewa tersebut diantaranya; Pertama, berfungsi sebagai rumah bagi warga, simpatisan, dan siapapun yang bersinggungan dengan Persyarikatan. Kedua, PCIM sebagai mata dan telinga Muhammadiyah di luar negeri. Berbagai informasi yang ada di luar negeri akan kami salurkan kepada Muhammadiyah di Indonesia dengan memanfaatkan segala media. Ketiga sebagai lidah, kaki, dan tangan Muhammadiyah di luar negeri di mana PCIM itu 
berada. (Zulhada, 2018) Keberadaan PCIM diharapakan dapat memaberikan warna keislaman yang berbeda dengan mainstream.

Langkah dalam melakukan internassionalisasi sebagai berikut; Pertama, untuk memenuhi permintaan "pasar" intelektual Timur Tengah, paling tidak perguruan tinggi di bawah Muhammadiyah, juga berbagai perguruan tinggi Islam yang lain, perlu segera memelopori gerakan penerjemahan buku, artikel, khazanah sosial, budaya dan intelektual Muslim Indonesia yang berkualitas ke dalam bahasa Arab berstandar akademik tinggi, readable bagi kalangan intelektual dan akademisi pengguna bahasa Arab sebagai medium of teaching dan communication-nya. Dengan begitu, sharing experience dan transfer of knowledge tentang pengalaman unik dan genuine tentang perjumpaan keindonesiaan dan keislaman dapat diakses di Timur Tengah dan beberapa negara pada belahan dunia lain. Ini akan merupakan sumbangan yang tidak ternilai harganya bagi kebudayaan Islam dan peradaban dunia. Mendirikan perguruan tinggi, yang menggunakan bahasa Inggris sebagai medium of instruction-nya. Asrama (dormitory) adalah salah satu syarat penting yang tidak dapat ditinggalkan dan berbagai universitas Muhammadiyah besar telah memilikinya. Memang perlu ada "sayap" persyarikatan dan itu adalah Perguruan Tinggi, yang mulai memikirkan kemungkinan merealisasikan mimpi besar ini. Ketiga, berpikir out of the box berani keluar dari zona nyaman dalam berpikir tentang pemikiran sosial, agama dan pendidikan. Perubahan cara berpikir dan mentalitas seperti itu yang dapat mengantarkan mereka dan jaringan internasionalnya seperti saat sekarang ini dalam upaya menginternasionalisasi visi dan misi kependidikannya. Cara berpikir, mind set, dan mentalitas kaum muda intelektual Muslim pada khususnya dan pemuda Indonesia dimana pun berada adalah bagian tidak terpisahkan dari warga dunia (world citizenship). (Abdullah, 2016)

Perintisan Internalisasi yang dilakukan oleh Muhammadiyah, dengan cara megembangkan pendidikan di luar negeri yang diantaranya; melalui realisasi Markas Muhammadiyah di Kairo yang juga menjedi sarana pendidikan usia dini melalui aman Kanak-Kanak (TK) Aisyiyah Bustanul Athfal (ABA) yang telah beroperasi sejak 2003. Selanjutnya Muhammadiyah juga telah mulai mengoperasikan sarana pendidikan dasar dan menengah di Australia. Saat ini, lahan milik Muhammadiyah di Melbourne seluas 10 hektare tengah dipersiapkan pusat pendidikan Muhammadiyah serta Islamic Centre, mendirikan konsorsium Universitas Muhammadiyah di Malaysia dengan menggunakan bahasa Inggris dan Arab. (Nashir, 2018) Selain itu, Muhammadiyah sudah resmi tercatat sebagai anggota Ecosoc, sebuah lembaga sosial dan ekonomi Perserikatan Bangsabangsa (PBB). Muhammadiyah memiliki organisasi mitra (sister organization), Muhammadiyah mulai melakukan kegiatan kemanusiaan di Philipina, Myanmar, Palestina lewat Lazismu dan MDMC. Muhammadiyah memberikan beasiswa bagi mahasiswa negara sahabat untuk studi Sarjana dan Master di beberapa Perguruan Tinggi Muhammadiyah (PTM), dan tokoh baik sebagai pribadi maupun pimpinan aktif dalam berbagai forum internasional, baik yang bersifat akademik maupun strategic. (Mu'ti 2018)

\section{SIMPULAN DAN SARAN}

Globalisasi sebagai realitas sosial yang mencair raung, waktu dan teritoroal Negara dengan keterbukaan informasi, menjadikan keislaman Indonesia sebagai persfetif wajah keislaman dunia. Kesilaman di Indonesia unik, mewarnai, selaras dan berkelindan dengan demokrasi khususnya organisasi keagamaan Muhammadiyah. Dalam rangka mengglobalkan keislaman Indonesia diperlukan internasionalisasi dengan cara yang dilaukan oleh Muhammadiyah mendirikan Pimpinan Cabang Istimewa, mendirikan amal usaha sampai dengan perguruan tinggi. Tingkat PAU di Mesir, dasar dan menengah di Asutralia dan Perguruan tinggi di Malaysia. Selain itu, Muhammadiyah juga berkerjasama dengan organisasi mitra PBB yang berkaitan dengan benca dan pengungsian. Gerakan yang dilakukan oleh Muhamadiyah merupakan bentuk sumbangsih Muhammadiyah terhadap peradaban di dunia agar menjadi lebih baik.

\section{DAFTAR RUJUKAN}

Ajid Thohir 2014, Sirah Nabawiyah: Nabi Muhammad dalam Ilmu Sosial dan Humaniora, Bandung: Marja

Falahuddin. 2019. Kuliah Kemuhammadiyahan. Mataram: LP3IK UMMAT.

Zakiyudin Baidhawy dan Azaki Khoirudin, 2017, Etika Muhamvmadiyah dan Spirit Peradaban, Yogyakarta: Suara Muhammadiyah

Budi Sujati, 2018, Sejarah Perkembangan Globalisasi dalam Dunia Islam, dalam Nalar Jurnal Pemikiran Islam, Vol. 2, No. 2, Desember

Haedar, Nashir. 2021. Tajdid Organisasi Muhammadiyah di Era Perubahan. Suara Muhammadiyah. Yogyakarta; edisi 9. 1-15 Mei 2021

Indra Kusumawardhana, 2017, Dari Internasionalisme Ke Globalisasi: What Next?, Jurnal Populis, Vol.2, No.3, Juni. 
M. Abdul Fatah Santoso, 2016, Internasionalisasi Konsep Purifikasi dalam Manhaj Tarjih Muhammadiyah, Jurnal Muhammadiyah Studies, Volume 1 No.1 Juli

M. Amin Abdullah, 2016, Peluang dan Tantangan Internasionalisasi Pemikiran Muhammadiyah, Jurnal Muhammadiyah Studies, Volume 1 No.1 Juli.

Mappanyompa, H. (2019). Pengaruh Pendidikan Kemuhammadiyahan. Ibtida'iy Journal PGM, 4(1), 1-97.

Warsisto Raharjo Jati, 2013, Memahami Globalisasi sebagai Evolusi Kapitalisme, Jurnal Global \& Strategi, Tahun 7 Nomor 2

Abdul Mu'ti, 2018, Internasionalisasi Gerakan Muhammadiyah Sejauh Mana? dalam https://klikmu.co.id

Abdul Mu'ti, 2021. Aktualisasi Manhaj Islam Berkemajuan.

https://republika.co.id/berita/nasional/sangpencerah/17/06/13/orhht1291-aktualisasimanhaj-islam-berkemajuan di akses pada tanggal 26 Maret 2021.

Haedar Nashir, 2018, Muhammadiyah di Kancah Global, dalam Selasa, 17 April dalam https://www.republika.co.id

Keputusan Muktamar Muhammadiyah, 2000, Pedoman Hidup Islami Warga Muhammadiyah

Sony Zulhada, 2018, Muhammadiyah Miliki 23 Pimpinan Cabang Istimewa di Luar Negeri, Ini Fungsi Utamanya, dalam https://klikmu.co.id

Syaiful Bakhir. 2021. Muhammadiyah dan tantangan global. https://www.republika.co.id/berita/ nybajb 219/muhammadiyah-dan-tantanganglobal di akses pada. 